\title{
Placenta-specific protein 1 (PLAC1) is a unique onco- fetal-placental protein and an underappreciated therapeutic target in cancer
}

\author{
Eric J. Devor ${ }^{1,2 *}$ \\ ${ }^{1}$ Department of Obstetrics and Gynecology, University of Iowa Carver College of Medicine, USA \\ ${ }^{2}$ Holden Comprehensive Cancer Center, University of Iowa Hospitals and Clinics, USA
}

\begin{abstract}
Placenta-specific protein 1 (PLAC1) is an X-linked gene whose expression is almost exclusively limited to placental trophoblasts. Its expression profile and evolutionary history suggest that it is important in the proper establishment and maintenance of a healthy placenta and a successful gestation throughout the Eutheria through promoting invasiveness, migration and proliferation of placental tissue. For the same reasons, PLAC1 expression has been found to be co-opted in a variety of cancers. For reasons less understood, it is also expressed in developing embryos. Thus, PLAC1 is the only known member of a class of proteins termed "onco-fetal-placental."
\end{abstract}

\section{Introduction}

Placenta-specific protein 1 (PLAC1) is a small (212 amino acid), secreted cell surface protein that was discovered because its location on the human and mouse X-chromosome coincided with genes suspected of being involved in placental and fetal pathology [1]. Since its first identification more than 15 years ago, PLAC1 has been studied by a few dedicated laboratories that have produced evidence linking PLAC1 not only to pathologies like placentomegaly and intrauterine growth restriction, but also to preeclampsia and hydrocephalus. In addition, PLAC1 expression has been documented in a wide range of human cancers. Thus, it has been suggested that a high and constant PLAC1 presence is essential to a healthy gestation but it contributes to a poor outcome if it is co-opted in a cancer. These issues and others will be presented in this review with the aim of elevating awareness of PLAC1 to a level worthy of its unique place as the only known onco-fetalplacental protein.

\section{PLAC1 genomics}

The gene encoding human PLAC1 lies on the long arm of the $\mathrm{X}$-chromosome at Xq26. It consists of six alternately spliced exons spanning nearly $200 \mathrm{~kb}$ (Figure 1). The entire PLAC1 coding sequence is contained within Exon 6 and all alternative splices are limited to the 5 ' UTR. Thus, effectively, PLAC1 is an intronless gene (Figure 1). The PLAC1 gene is unique to and highly conserved in placental mammals. PLAC1 genomic organization, including both intron-exon structure and promoter sequences, is also highly conserved. Using the completed genome sequences of numerous placental mammals curated in ENSEMBL (www.ensembl.org), including human, horse, cow, sheep, pig, dolphin, cat, dog, mouse, squirrel and microbat, alignments and chromosome coordinates of all six PLAC1 exons display the same overall boundaries and spacing. In addition, many of the transcription factor binding sites found in the human gene are also conserved in other placental mammal species.

Two promoters, termed P1 (or Distal), located at Exon 1, and P2 (or
Proximal), located at Exon 4, have been identified with experimental evidence that transcripts are simultaneously produced from both promoters in cells that express PLAC1 mRNAs [2-4]. These transcripts have been termed P1L (containing Exons 1-2-5-6), P1S (containing Exons 1-5-6), and P2 (containing Exons 4-5-6) (Figure 1). All three transcripts have been repeatedly verified by transcript-specific qPCR and direct sequencing $[3,4]$. It is important to note that, beginning with the initial description of the two promoters [2], promoter preference has been reported in which transcripts in placental tissues are predominantly $\mathrm{P} 2$ transcripts while those produced in tumors are predominantly P1 transcripts. Given that the protein coding sequence is the same regardless of which promoter is being utilized most by the transcriptional machinery, the reason for this preferential transcription pattern remains unclear.

\section{PLAC1 phylogenetics}

From its initial description in the literature $[1,5]$ it has been accepted that PLAC1 is highly conserved and plays an important role in the proper establishment and maintenance of the placenta [6,7]. This consensus led to an in-depth phylogenetic study of the PLAC1 gene and its protein [8]. In that study, in which the PLAC1 coding sequence and its amino acid translation were determined on 25 placental mammal species representing nine crown orders of placental mammals (Eutheria), it was seen that both the nucleotide and amino acid sequences are indeed very highly conserved. Moreover, these data

Correspondence to: Eric J. Devor, Ph.D, Research Assistant Professor, CoDirector, Reproduction Science Research Division, Department of Obstetrics and Gynecology, University of Iowa Carver College of Medicine, 463A MRF, Iowa City, Iowa 52242, USA

Holden Comprehensive Cancer Center, University of Iowa Hospitals and Clinics, Iowa City, Iowa 52242, USA, Tel: 319-321-7695, E-mail: eric-devor@uiowa.edu

Received: April 22, 2016; Accepted: May 05, 2016; Published: May 09, 2016 


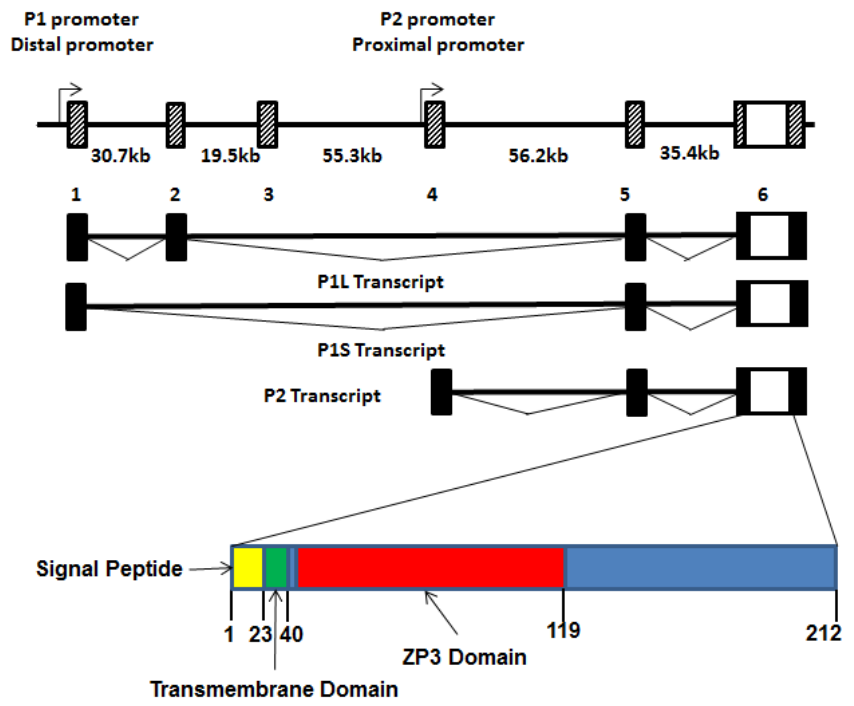

Figure 1. PLAC1 genomics

The genomic organization of the PLAC1 gene on human chromosome Xq26 is shown. The coding region and 3'UTR, along with a small segment of the 5'UTR, is contained entirely within Exon 6 . The preceding five exons comprise the remainder of an alternately spliced 5'UTR. The composition of the 5'UTR depends upon whether transcription starts at the distal promoter (P1) or the proximal promoter (P2). However, all three of the alternate transcripts are present in cells expressing PLAC1. Also shown is the PLAC1 protein which contains three conserved functional domains; signal peptide, transmembrane and ZP3.

permitted the demonstration that this level of conservation was due to stringent purifying selection operating throughout the Placentalia.

Phylogenetic analyses has been expanded to now include 54 placental mammal species representing twelve crown orders (Figure 2A). In addition to increasing statistical support for the phylogenetic relationships among the placental mammals, inclusion of 29 additional placental species revealed a number of lineage-specific mutations altering the length of the relatively unconserved carboxy-terminal end of the PLAC1 protein (Figure 2A). Analyses of the original 25 species showed that the focus of selection in the PLAC1 gene was the transmembrane domain and the interactive ZP3 domain, and this was fully reinforced by the subsequent sequence determinations presented here.

Placenta-specific expression suggests two potential origins for the PLAC1 gene. The first is that PLAC1 descended from an ancestral gene not likely involved in placental establishment and maintenance. Alternatively, PLAC1 may have arisen de novo along with the placenta itself. In order to address this question, a consensus PLAC1 nucleotide sequence encoding the first 119 amino acids was assembled in silico and used to examine the genomes of several non-placental species. Marsupials were represented by the opossum (Monodelphis domestica) and the wallaby (Macropus eugenii); the only available monotreme is the platypus (Ornithorhynchus anatinus); birds were represented by the chicken (Gallus gallus) and the finch (Taeniopygia guttata) and fish by the zebrafish (Danio rerio) and the stickleback (Gasterosteus arculeatus). None of these species returned any evidence of a sequence or sequence fragments that could be considered ancestral to PLAC1, particularly within the syntenic region bounded by PHF6 and F9 (Figure 2B). While clearly not exhaustive, these data are consistent with a conclusion that PLAC1 arose de novo in the placental mammal genome. Moreover, all genomic and phylogenetic data considered together point to the emergence of PLAC1 some 165 million years ago, based upon the dating of the first true placental mammal Juramaia sinensis [9].

Direct verification of placental PLAC1 expression by RT-PCR and sequencing has been carried out so far in human, mouse, cow, cat, dog, rabbit and pig (unpublished data). Hopefully, more species will be added in the future which will more fully validate the suggestion that PLAC1 is expressed in all placental mammals.

\section{PLAC1 function}

PLAC1 was discovered as a result of sequencing the region around the hypoxanthine ribosyltranferase 1 (HPRT) gene on the human $\mathrm{X}$-chromosome based upon the suggestion that a placenta-specific protein is present in that region in the mouse genome [1]. This effort identified the PLAC1 gene in the human genome and the suspected mouse ortholog Plac1. Soon after, it was shown that PLAC1 is expressed throughout gestation in both mouse and human $[5,10]$. Those studies correctly proposed that PLAC1 expression is trophoblast-specific and were the first to conclude that it is a crucial factor in normal placental establishment and maintenance. This conclusion was substantiated

A.

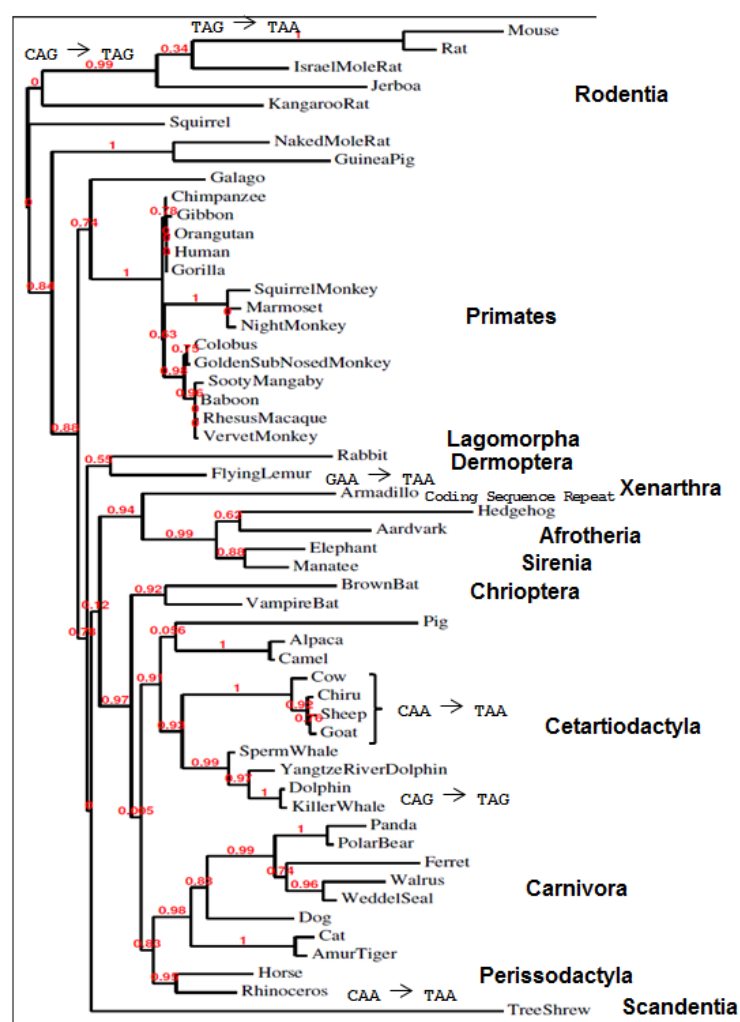

B.

\begin{tabular}{|c|c|c|c|c|c|}
\hline & PHF6 & HPRT1 & PLAC1 & $\mathrm{ZIC} 3$ & F9 \\
\hline Placental mammals & $\mathrm{x}$ & $\mathrm{x}$ & $\mathrm{x}$ & $\mathrm{x}$ & $\mathrm{x}$ \\
\hline Marsupials (Chr X) & $\mathrm{x}$ & $\mathrm{x}$ & & $\mathrm{x}$ & $\mathrm{x}$ \\
\hline Montremes (chr X) & $\mathrm{x}$ & $x$ & & $\mathrm{x}$ & $\mathrm{x}$ \\
\hline Birds (Chr 4, 4A) & $\mathrm{x}$ & $x$ & & $x$ & $\mathrm{x}$ \\
\hline Fish (Chr 14,7) & $\mathrm{x}$ & $\mathrm{x}$ & & $\mathrm{x}$ & $\mathrm{x}$ \\
\hline
\end{tabular}

Figure 2. PLAC1 Phylogenetics

A. A PLAC1 phylogeny containing 54 placental mammal species representing twelve crown orders. Also shown are several well verified mutations occurring after residue 120 leading to lineage-specific variation in the post-ZP3 carboxy-terminal end of the protein. B. Conservation of a syntenic X-chromosome region spanning more than $400,000,000$ years showing that PLAC1 first appears in animal genomes with the emergence of placental mammals $165,000,000$ years ago. 
when expression was precisely localized to the apical region of syncytiotrophoblasts, the invasive component of the developing embryo [11]. Somewhat later it was established that the PLAC1 gene is paternally imprinted in both humans and mice [7].

The clearly crucial role of PLAC1 in implantation and maintenance of the developing placenta naturally raised the question of its potential role in gestational disorders. RNA interference (RNAi) knockdown of PLAC1 in trophoblast-derived HTR8 cells resulted in significant ablation of both the invasive and migratory abilities of these cells, thus potentially implicating PLAC1 dysfunction in a variety of disorders including unexplained infertility, pre-term birth and preeclampsia [12].

As trophoblasts are of fetal origin, the discovery of fetal-specific RNA in maternal plasma $[13,14]$ opened up the possibility of noninvasive PLAC1 mRNA assays for diagnostic purposes. A study of peripheral PLAC1 mRNA levels and Doppler-determined uterine artery resistance in women in their $37^{\text {th }}$ week of gestation revealed a significant positive correlation with this potential preeclampsia correlate [15]. Studies of the clinical preeclampsia indicators blood pressure and proteinuria also revealed significant positive correlations $[16,17]$. A more recent analysis of PLAC1 in maternal peripheral circulation among women who subsequently developed preeclampsia demonstrated significantly increased mRNA even in the second trimester [18]. Numerous studies have provided evidence that fetal RNAs in maternal circulation originate from trophoblast apoptosis and are, therefore, a monitor of placental health [19-22]. In a direct extension of this notion, we recently made the novel discovery that term placental tissues from women diagnosed with preeclampsia have significantly lower expression of PLAC1 compared with tissues from uncomplicated, full-term deliveries [23]. This study also implicated hypoxia-mediated down-regulation of MED1/TRAP transcription mediator complex as a major factor in the decreased PLAC1 expression. Thus, placental insufficiency, regardless of cause, may be reflected in both decreased levels of PLAC1 in the tissues and increased levels in the maternal circulation.

Finally, much of has been deduced about the role of PLAC1 in Eutherian gestation has come from studies of placentas that have already been established in the uterus. However, two studies of unexplained infertility both note the presence of anti-PLAC1 antibodies in the circulation of women with repeated implantation failure [24,25]. Thus, even though the point at which detectable levels of PLAC1 first appear is very early in gestation, if PLAC1 is involved in failure of an embryo to even implant, then PLAC1 must initially turn on as early as the blastocyst stage.

\section{PLAC1 and cancer}

The decade and a half since the discovery of PLAC1 has served to fully establish it as an important component in both normal and abnormal placentation. However, very early on PLAC1 expression was discovered in a variety of cancers, and it is here that it has taken on a role as a potentially attractive therapeutic target, particularly in cancers affecting women. The first evidence of PLAC1 expression in a tumor was published in 2006 [26]. However, several independent investigations demonstrating that a variety of human cancers induce PLAC1 expression appeared over the next two years. One group, searching for genes that are silent in most cells but robustly expressed in cancer cells, chose to focus on gametogenic and trophoblast cells [27]. The gene that immediately stood out was PLAC1. Screening a series of 62 primary human breast tumors by RT-PCR showed that the vast majority display high levels of PLAC1 message. High PLAC1 message was also shown in a series of 37 cancer cells lines representing six different cancers. However, the most notable result in this study was that RNAi-mediated PLAC1 knockdown in MCF-7 and BT-549 breast cancer cells significantly reduce both invasiveness and proliferation. Further, abrogation of proliferation was tied to a G1-S cell cycle block. Soon after this report, similar findings in non-small cell lung cancer (NSCLC) were reported [28]. In addition, this group added evidence of PLAC1 expression in a further 66 cancer cell lines extending the scope of PLAC1 expression an additional ten cancer types.

These papers were followed by evidence of PLAC1 expression in hepato-cellular carcinoma [29], colorectal cancer [30], ovarian cancer [31], gastric cancers [32], uterine cancer [3] and prostate cancer [33]. In all of these studies there were hints that PLAC1 expression positively correlates with clinical features, including stage and grade and survival. A clear relationship between relative PLAC1 mRNA level and stage was reported in uterine cancers [3] and between PLAC1 protein, as measured by immunohistochemistry, and Gleason Score in prostate cancer [33]. Further, in the latter study there was a marked progression of PLAC1 expression from little to none in non-neoplastic/nonhyperplastic prostate tissue through steady increases in benign prostate hyperplasia (BPH), through the potential cancer precursor state highgrade prostate intraepithelial neoplasia (HPIN) and, ultimately, to frank prostate carcinomas. A recent study of gastric adenocarcinoma [32], also using PLAC1 immunohistochemistry, reported that 73 of 119 patients were positive for PLAC1 and that they had worse overall survival than did the 46 remaining patients who were PLAC1 negative. Apart from these few studies, however, no definitive evidence linking PLAC1 mRNA or protein levels in cancers to specific clinical outcomes has been offered, though such studies are under way.

Of course, even if definitive links between PLAC1 and specific clinical outcomes are established, the question remains as to what to do about it. One possible answer lies in the fact that PLAC1 is a cell surface protein. This means that it could be a target for immunotherapy. Such a suggestion has been proffered before in studies in which anti-PLAC1 antibodies were detected in the sera of a small percentage of patients diagnosed with NSCLC and hepatocellular carcinoma [28,29]. A small study of colorectal cancers reported that survival among patients with a positive anti-PLAC1 antibody response is better than among nonresponders [30]. Interestingly, the same group reported the opposite result in a sample of 119 gastric carcinoma patients some years later [32]. Such apparently contradictory findings are common in cancer research, underscoring the necessity to validate findings from one cancer type in other cancers. Nonetheless, a consensus among those who have investigated PLAC1 in cancer is that anti-PLAC1 immunotherapy is a useful avenue to pursue, particularly in cancers of the breast, uterus and ovary where the prevalence of PLAC1 induction appears to be the highest. The same conclusion was reached for prostate cancer [33].

Finally, assuming that it is reasonable to extrapolate from data indicating that PLAC1 is expressed in the placentas of all eutherian mammals, the question arises as to whether PLAC1 may also be induced in non-human cancers. To address this, an effort was initiated to collect relevant non-human tumors. The search has succeeded so far in obtaining a small number of mammary tumors from dogs and cats, two uterine tumors from rabbits as well as a malignant mixed Müllerian tumor (MMMT) in a rabbit [34]. Non-cancerous tissues were also obtained from these species and, using species-specific primers and other appropriate controls, unequivocal evidence that PLAC1 expression is induced in non-human cancers was 
obtained (Figure 3). This expansion into veterinary oncology only serves to enhance the appeal of PLAC1 as a potential therapeutic target in cancers either exclusively or predominantly affecting females.

\section{PLAC1 in fetal development}

The term "onco-fetal-placental protein," as used in the title of this review has been uniquely linked with PLAC1 but only for the past few years. While the roles of PLAC1 as a monitor of placental health and as an important co-opted gene in a number of cancers have been established as the result of more than fifteen years of careful experimentation, the discovery of fetal PLAC1 expression was accidental. In the process of characterizing a Plac1 knockout mouse model, expression was detected in fetal lungs, kidney, intestine, liver, heart and particularly in brain [35]. This observation was confirmed in human fetal tissues soon after [4]. Moreover, in the original study, it was found that Plac1 ablation resulted in a lethal hydrocephalus in $20 \%$ of surviving $\mathrm{X}^{\mathrm{m}-} \mathrm{Y}$ knockout males and in $10-15 \%$ of $\mathrm{X}^{\mathrm{m}-\mathrm{X}}$ females [35]. Thus, PLAC1 appears to play a role in normal fetal development, particularly the fetal brain. Just what this role is and what the mechanisms are awaits further studies.

\section{Conclusion}

A decade ago, Dr. Lloyd Old wrote an editorial entitled "Cancer is a Somatic Cell Pregnancy" [36]. In that essay he reiterated the opinion of embryologist Dr. John Beard, who in the late $19^{\text {th }}$ century pointed out the near functional identity of tumors and placentas [37]. To Beard, both tumor cells and trophoblasts are proliferative, migratory and invasive and, though he was unaware of these cellular processes, immune suppression and angiogenesis can now be added to the list. To Dr. Old, it was reasonable to assume that cancers and placentas would produce specific proteins that would confer on their cells the properties listed above. Thus far, PLAC1 is the only known member of the class of proteins that Old termed "onco-placental" and now that "fetal" has been added to the modifier it makes this gene even more distinctive

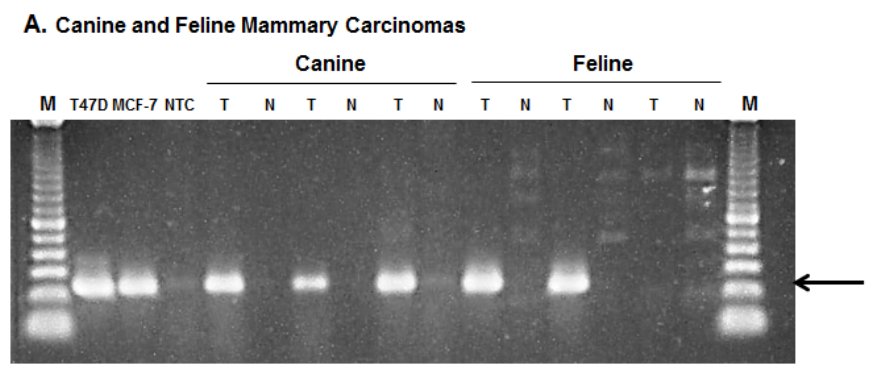

B. Rabbit Uterine Carcinomas

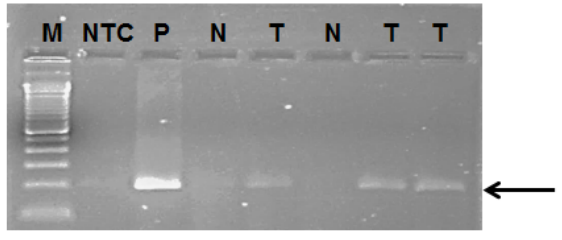

Figure 3.PLAC1 expression in non-human cancers

A. Species-specific, sequence verified PLAC1 RT-PCR amplicons in three of three canine and two of three feline mammary carcinomas. Each of these is paired with non-cancerous tissues from the same patient. Human breast cancer cell lines T47D and MCF-7 were used as positive controls. B. Species-specific, sequence verified PLAC1 RT-PCR amplicons from two rabbit uterine carcinomas (Lanes 5,7) with matched non-cancerous tissues (Lanes 4,6) and a malignant mixed Müllerian tumor from a dwarf rabbit [34]. The control in Lane 3 is rabbit placental tissue.

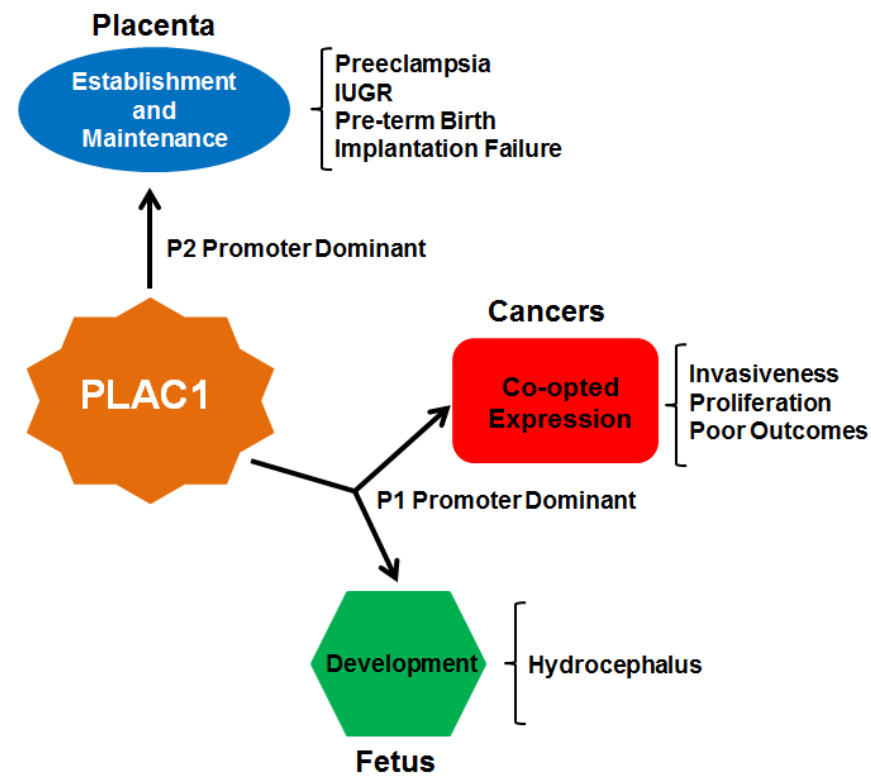

Figure 4.A summary of PLAC1 influences

PLAC1 is known to be expressed normally in the mammalian placenta and in fetal tissues. Decreased or ablated expression in these tissues is associated with a number of pathologic outcomes including preeclampsia and at least one major birth defect. In an opposite effect, induction of PLAC1 expression in solid tumors aids in the promotion of cancer growth and invasiveness. Thus monitoring PLAC1 expression in gestation and in cancers could lead to more effective clinical interventions and better patient outcomes.

\section{(Figure 4).}

It can be seen that PLAC1 expression, or the lack of expression, can have effects both positive and negative. In the placenta, PLAC1 expression is a positive, signaling good placental health, while in a cancer it is the opposite, possibly signaling worse outcomes among those patients whose cancers express it. In fetal development, the only notable finding to date is that loss of Placl can be catastrophic for a developing murine brain. Cancers, including uterine, ovarian and cervical cancers, induce expression of PLAC1 for precisely the same reason that trophoblasts express it- to aid in migration, invasiveness and proliferation. The sporadic but nonetheless important work done to date on understanding the role of PLAC1 in cancers, particularly the experiments done in breast cancer cells in which PLAC1 is ablated and the cellular proliferation, migration and invasiveness are impaired or ablated as a result $[27,38]$, clearly nominate this gene as a therapeutic target. The potential for PLAC1 as an immunotherapy target is tantalizing. The fact that PLAC1 is induced in these cancers even in non-human species furthers strengthens it as an attractive "Achilles heel" that should be exploited.

\section{Acknowledgements}

This work was supported in part by NIH Grant RO1CA99908 and the University of Iowa Carver College of Medicine Department of Obstetrics and Gynecology Research Development Fund. The author acknowledges the Department of Obstetrics and Gynecology Women's Health Tissue Repository and the Gynecologic Malignancy Repository (Dr. Donna Santillan, Director) as well as the continued invaluable assistance of the University of Iowa Institute of Human Genetics Genomics Facility (in particular Garry Hauser and Mary Boes). The author is also grateful for the generosity of Dr. Susan Lana of the Flint Animal Cancer Center at Colorado State University, Dr. 
Sandra Schoeniger of the Institute of Pathology, Faculty of Veterinary Medicine, Leipzig University, Germany, and Drs. Tanja Švara and Marko Zadravec of the Veterinary Faculty of Ljubljana, Slovenia for providing the veterinary cancer and control tissues.

\section{References}

1. Cocchia M, Huber R, Pantano S, Chen EY, Ma P, et al. (2000) PLAC1, an Xq26 gene with placenta-specific expression. Genomics 68: 305-312.[Crossref]

2. Chen Y, Moradin A, Schlessinger D, Nagaraja R (2011) RXR $\alpha$ and LXR activate two promoters in placenta- and tumor-specific expression of PLAC1. Placenta 32: 877-884. [Crossref]

3. Devor EJ, Leslie KK (2013) Theoncoplacental gene placenta-specific protein 1 is highly expressed in endometrial tumors and cell lines. Obstet Gynecol Int 2013: 807849.[Crossref]

4. Devor EJ, Reyes HD, Santillan DA, Santillan MK, Onukwugha C, et al. (2014) Placenta-specific protein 1: a potential key to many oncofetal-placental OB/GYN research questions. Obstet Gynecol Int 2014: 678984.[Crossref]

5. Fant M, Weisoly DL, Cocchia M, Huber R, Khan S, et al. (2002) PLAC1, a trophoblastspecific gene, is expressed throughout pregnancy in the human placenta and modulated by keratinocyte growth factor. Mol Reprod Dev 63: 430-436.[Crossref]

6. Fant ME, Fuentes J, Kong X, Jackman S (2014) The nexus of prematurity, birth defects, and intrauterine growth restriction: a role for plac1-regulated pathways. Front Pediatr 2: 8.[Crossref]

7. Jackman SM, Kong X, Fant ME (2012) Plac1 (placenta-specific 1) is essential for normal placental and embryonic development. Mol Reprod Dev 79: 564-572.[Crossref]

8. Devor EJ (2014) Placenta-specific protein 1 is conserved throughout the Placentalia under purifying selection. Scientific World Journal 2014: 537356.[Crossref]

9. Luo ZX, Yuan CX, Meng QJ, Ji Q (2011) A Jurassic eutherian mammal and divergence of marsupials and placentals. Nature 476: 442-445.[Crossref]

10. Massabbal E, Parveen S, Weisoly DL, Nelson DM, Smith SD, et al. (2005) PLAC1 expression increases during trophoblast differentiation: evidence for regulatory interactions with the fibroblast growth factor-7 (FGF-7) axis. Mol Reprod Dev 71: 299304.[Crossref]

11. Fant M, Barerra-Saldana H, Dubinsky W, Poindexter B, Bick R (2007) The PLAC1 protein localizes to membranous compartments in the apical region of the syncytiotrophoblast. Mol Reprod Dev 74: 922-929.[Crossref]

12. Chang WL, Yang Q, Zhang H, Lin HY, Zhou Z, et al. (2014) Role of placenta-specific protein 1 in trophoblast invasion and migration. Reproduction 148: 343-352.[Crossref]

13. Poon LL, Leung TN, Lau TK, Lo YM (2000) Presence of fetal RNA in maternal plasma. Clin Chem 46: 1832-1834.[Crossref]

14. Ng EK, Tsui NB, Lau TK, Leung TN, Chiu RW, et al. (2003) mRNA of placental origin is readily detectable in maternal plasma. ProcNatl Acad Sci U S A 100: 4748-4753. [Crossref]

15. Farina A, Concu M, Banzola I, Tempesta A, Vagnoni S, et al. (2006) PLAC1 mRNA in maternal blood correlates with Doppler waveform in uterine arteries in normal pregnancies at the second and third trimester. Ann N Y Acad Sci 1075: 130-136. [Crossref]

16. Purwosunu Y, Sekizawa A, Farina A, Wibowo N, Okazaki S, et al. (2007) Cell-free mRNA concentrations of CRH, PLAC1, and selectin-P are increased in the plasma of pregnant women with preeclampsia. Prenat Diagn 27: 772-777.[Crossref]

17. Kodama M, Miyoshi H, Fujito N, Samura O, Kudo Y (2011) Plasma mRNA concentrations of placenta-specific 1 (PLAC1) and pregnancy associated plasm protein A (PAPP-A) are higher in early-onset than late-onset pre-eclampsia. J Obstet Gynecol Res 37: 313-318.[Crossref]

18. Zanello M, Sekizawa A, Purwosunu Y, Curti A, Farina A (2014) Circulating mRNA for the PLAC1 gene as a second trimester marker (14-18 weeks' gestation) in the screening for late preeclampsia. Fetal Diagn Ther 36: 196-201.[Crossref]

19. van Wijk IJ, van Vugt JMG, Könst AAM, Mulders MAM, Florijn WJ, et al.(1998) Identification of HASH2-positive extravilluostrophoblast cells in the peripheral blood of pregnant women. Trophoblast Res 11: 23-33.

20. Taniguchi R, Farina A, Sugito Y, Matsuoka R, Iwasaki M (2000) Trophoblastic cells expressing human chorionic gonadotropin genes in peripheral blood of patients with trophoblastic disease. Life Sci 66: 1539-1601.[Crossref]
21. Austgulen R, Isaksen CV, Chedwick L, Romundstad P, Vatten L, et al. (2004) Preeclampsia: associated with increased syncytial apoptosis when the infant is small-forgestational-age. J Reprod Immunol 61: 39-50.[Crossref]

22. Sekizawa A, Koizumi T, Das H, Chakraborty S, Sugimoto T, et al. (2004) Proteinuria and hypertension are independent factors affecting fetal DNA values: a retrospective analysis of affected and unaffected patients. Clin Chem 50: 221-224.[Crossref]

23. Devor EJ, Santillan DS, Scroggins SM, Santillan MK (2016) Placenta-specific protein 1 (PLAC1) expression is significantly down-regulated in preeclampsia via a hypoxiamediated mechanism. Am J Obstet Gynecol (submitted).

24. Kotto-Kome AC, Silva C, Whiteman V, Kong X, Fant ME (2011) Circulating antiPLAC1 antibodies during pregnancy in women with reproductive failure: A preliminary analysis. ISRN Immunol: 530491.

25. Matteo M, Greco P, Levi Setti PE, Morenghi E, De Rosario F, et al. (2013) Preliminary evidence for high anti-PLAC1 antibody levels in infertile patients with repeated unexplained implantation failure. Placenta 34: 335-339.[Crossref]

26. Chen J, Pang XW, Liu FF, Dong XY, Wang HC, et al. (2006) [PLAC1/CP1 gene expression and autologous humoral immunity in gastric cancer patients]. Beijing $\mathrm{Da}$ Хие Хие Bao 38: 124-127.[Crossref]

27. Koslowski M, Sahin U, Mitnacht-Kraus R, Seitz G, Huber C, et al. (2007) A placentaspecific gene ectopically activated in many human cancers is essentially involved in malignant cell processes. Cancer Res 67: 9528-9534.[Crossref]

28. Silva WA, Gnjatic S, Ritter E, Chua R, Cohen T, et al. (2007) PLAC1, a trpohiblastspecific cell surface protein, is expressed in a range of human tumors and elicits spontaneous antibody responses. Cancer Immunity 7: 18.[Crossref]

29. Dong XY, Peng JR, Ye YJ, Chen HS, Zhang LJ, et al. (2008) PLAC1 is a tumor-specific antigen capable of eliciting spontaneous antibody responses in human cancer patients. Int J Cancer 122: 2038-2043. [Crossref]

30. Liu FF, Dong XY, Pang XW, Xing Q, Wang HC, et al. (2008) The specific immune response to tumor antigen $\mathrm{CP} 1$ and its correlation with improved survival in colon cancer patients. Gastroenterology 134: 998-1006.[Crossref]

31. Tchabo NE, Mhawech-Fauceglia P, Caballero OL, Villella J, Beck AF, et al. (2009) Expression and serum immunoreactivity of developmentally restricted differentiation antigens in epithelial ovarian cancer. Cancer Immun 9: 6.[Crossref]

32. Liu F-F, Shen D, Kang X, Zhang C, Song Q (2015) Newtumor antigen PLAC1/ $\mathrm{CP1}$, a potentially useful prognostic marker and immunotherapy target for gastric adenocarcinoma. J Clin Pathol 2015-202978.[Crossref]

33. Ghods R, Ghahremani MH, Madjd Z, Asgari M, Abolhasani M, et al. (2014) High placenta-specific 1/low prostate-specific antigen expression pattern in high grade prostate adenocarcinoma. Cancer Immunol Immunother 63: 1319-1327.[Crossref]

34. Zadravec M, GombaÄ M, RaÄnik J, ZormanRojs O, PogaÄnik M, et al. (2012) Uterine heterologous malignant mixed Mülleriantumor in a dwarf rabbit (Oryctolaguscuniculus). $J$ Vet Diagn Invest 24: 418-422.[Crossref]

35. Kong X, Jackman SM, Fant ME (2013) Plac1 (placenta-specific 1) is widely expressed during fetal development and is associated with a lethal form of hydrocephalus. Birth Defects Res A Clin Mol Teratol 97: 571-577.[Crossref]

36. Old LJ (2007) Cancer is a somatic cell pregnancy. Cancer Immun 7: 19.[Crossref]

37. Moss RW (2008) The life and times of John Beard, DSc (1858-1924). Integr Cancer Ther 7: 229-251.[Crossref]

38. Koslowski M, Türeci O, Biesterfeld S, Seitz G, Huber C, et al. (2009) Selective activation of trophoblast-specific PLAC1 in breast cancer by CCAAT/enhancerbinding protein beta (C/EBPbeta) isoform 2. J Biol Chem 284: 28607-28615.[Crossref]

Copyright: (C2016 Devor EJ. This is an open-access article distributed under the terms of the Creative Commons Attribution License, which permits unrestricted use, distribution, and reproduction in any medium, provided the original author and source are credited. 